\title{
Geographical Information System (GIS) in Jalandhar City as a Tool of Network Analysis
}

\author{
Harcharan Singh, Sachin Suryawanshi
}

\begin{abstract}
Jalandhar City's Road Network Analysis is conducted to evaluate the roadways network using the Geographic Information System and remote sensing. Using sophisticated technology, i.e. RS \& GIS, Roadways network assessment has now become prevalent practice in many fields of implementation in these environments. But the network of roadways, which is one of the spatial characteristics and is to be, analysed extensively using GIS. The primary issue in the assessment of the roadways network is the analysing and measuring the services (like as Schools, Hospitals and Fire Stations) efficiency in terms of timing and distance covered by the vehicle. GIS can assist in the storage, manipulation and analysis of a city's physical, social and economic information. GIS spatial query and mapping features can then be used by planners to analyse the current scenario in the urban traffic network evaluation of Jalandhar City in terms of their basic services for police department and many other departments also. Not only can the methodology be used on a straightforward street network assessment, it can also support multi-edge sources in modelling complicated multimodal networks. The following duties are covered by the studies and assessments: Select and develop the source workspace, identify the sources and their position in the network, model the connectivity, define characteristics and determine their values. It also outlined the following analyses: find the best path, find the nearest facility, find the service area and create the O-D cost matrix.
\end{abstract}

Keywords-GIS, Road Network analysis, Route Analysis and Service Areas.

\section{INTRODUCTION}

A network is a liner function scheme with the proper attribute for object flow. A network is an interconnected elements scheme, such as linking point's lines. Examples of networks include city-connected roads, interconnected streets at road

\footnotetext{
Manuscript revised June 5, 2019 and published on July 10, 2019 Harcharan Singh, AITP, Urban Planner \& GIS Expert, Alumni of GRD School of Planning, GNDU, Amritsar. Harcharanriar2016@gmail.com

Sachin Suryawanshi, GIS Expert, Alumni, University of Pune, Suryawanshi.s1@gmail.com
}

junctions, and sewer and A GIS feature called network analysis was used to calculate the time required for emergency vehicles to move from fire stations to distinct regions of the city. A significant implementation of network assessment is discovered in transport planning, where the problem could be to discover routes that correspond to certain requirements, such as finding the shortest or least cost route between two or more places, or to discover all places within the given travel price from a defined source. A GIS is traditionally representing the actual world in either one of two spatial models, vector-based, i.e. points, rows and polygons, or raster-based, i.e. constant grid ground cells. This research will explore the topic of network assessment in both the GIS raster and vector, to compare the two models of space. Network analysis is helpful for organizations managing or using networked equipment such as utilities, transmission and transportation systems. It is also possible to apply network analysis to retail store planning. Settling driving times, for example, can help determine retail store trade regions. Reducing driving times, for example, can help to determine the scheduling of retail stores. Settling driving times, for example, can help determine retail store trade regions. The network therefore offers the motion of individuals and products, the provision of facilities, the flow of services and data. Network tracking, network routing and network allocation are three main kinds of network assessment. A complicated topology that involves links, nodes, turns (e.g. through turn tables), paths (e.g. through dynamic segmentation) and terminal path changes can illustrate the traffic network. Some of the networks are fully interconnected (e.g., on the same highway, cars, busses, bicycles and pedestrians), some are only partially interconnected.

This analyst's network used was stored as a network dataset. From the sources participating in the network, a network dataset was developed. It includes sophisticated models of connectivity representing complicated situations, such as multimodal transport networks. It also has a wealthy attribute model for the network that helps model impedances, limitations, and hierarchy. The network dataset was constructed using simple features (lines and points) and turns. 


\section{AIM \& OBJECTIVE}

Aim: Jalandhar City's service area-based network assessment using GIS methods.

The purpose of this study is to create Jalandhar City's GIS-based urban traffic network assessment especially for police department. To this end, the study will pursue the following goals.

The objectives of this study are as follows:

- Selecting and creating the source workspace,

- Identifying the sources and the role they will play in the network,

- Connectivity modelling for management of the service of Police department for public,
- Identifying characteristics and determining their values, and their analysis [18].

\section{STUDY AREA}

Jalandhar city area is situated in central-northern portion over Punjab in India with location coordinates near to as $31^{\circ} 19^{\prime} \mathrm{N}$ latitudes \& $35^{\circ} 18^{\prime}$ E longitudes. Jalandhar city is an historic metropolis among the upper Indian ruler on Punjab. It's domestic in accordance with Devi Talab Mandir, a centuries-old Hindu house devoted according to the goddess Durga, along a pond regarded holy through devotees. The whitewashed Gurdwara Chhevin Patshahi is a region concerning revere because of Sikhs.

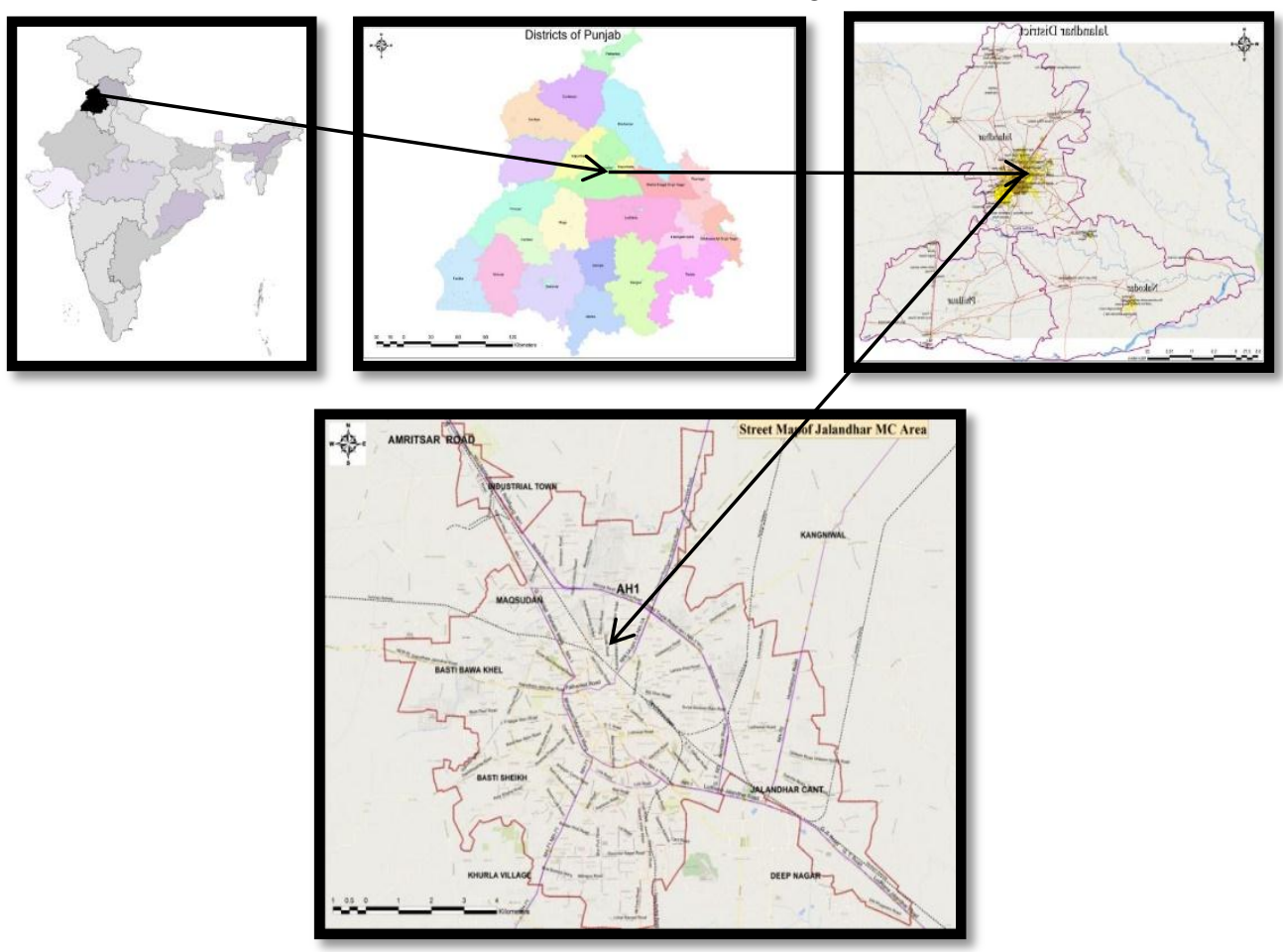

Figure 1: Location of Jalandhar City in India.

To the southeast lies St. Mary's Cathedral, a modern constructing including Punjabi architectural elements, 2 domed towers yet a pond. It stands at 56th function amongst Indian metropolitan cities. The quantity of population in Jalandhar city is 8.62 lakhs as per census 2011. The city varieties piece on the Trans Indo Gangetic plain, topography is virtually lucid or the ground is altogether fertile into the area. It is the hub of Medical institutes and Hospitals in Punjab and also called as the NRI City of Punjab. Maximum temperature varies beside $19.40 \mathrm{C}$ of January (winters) and 400C in May then June (summers). The minimum temperature varies from 6.20C within January (winters) and 250C in May then June (summers). The area received an average annual rainfall concerning as $569 \mathrm{~mm}$. Maximum rainfall is received beside the southwest monsoon. It is basically said to main hub for all economic activities and Sports goods industries in Punjab [16].

\section{MATERIALS AND METHODOLOGY}

A. Data Sources: In first phase of methodology the acquisitions of preferred data should be done. The data such as satellite images with good resolution or aerial photographs or toposheet. 


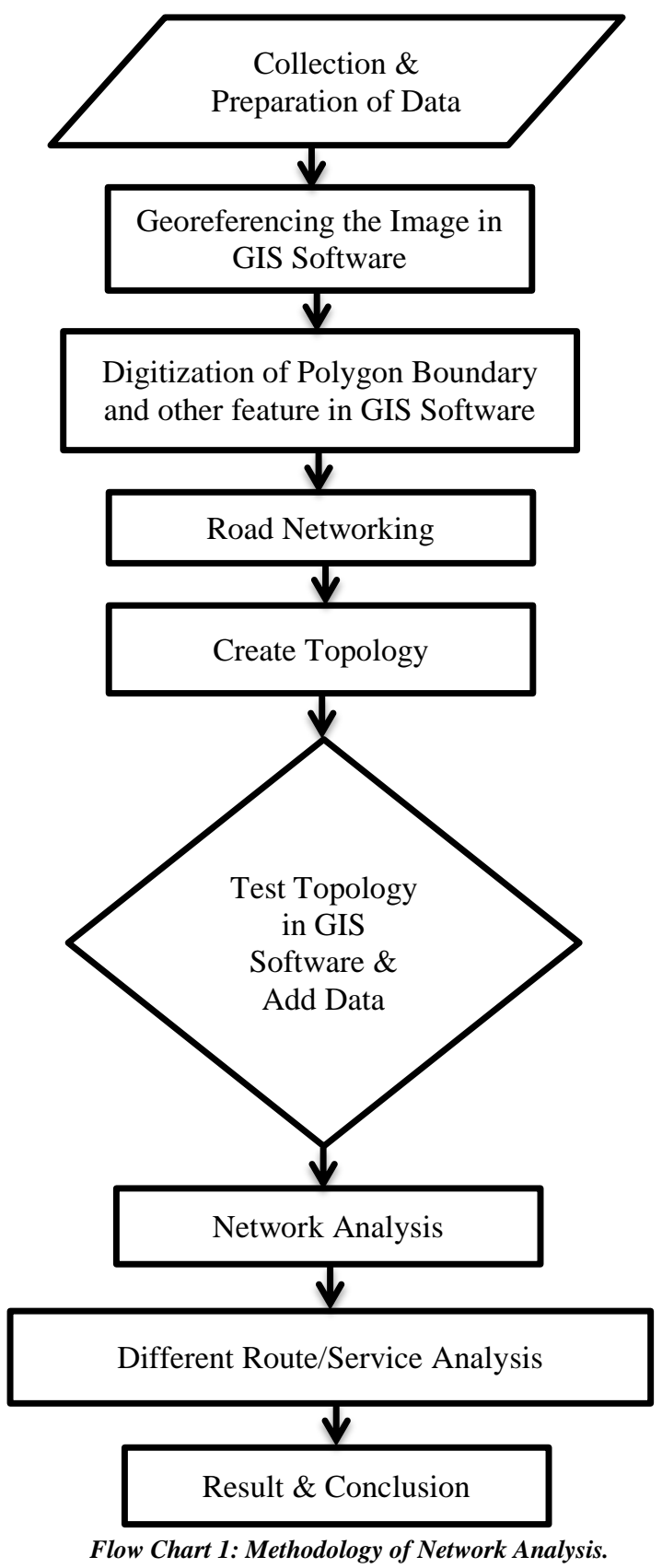

It should be Digitize with a defined zoom level, so all the features can be digitized in number of layers. In next phase the ground control points had taken of every Area of Interest (AOI) on the known roads / important places for georeferencing. If there is another registered image then image to image registration should be performed.

And if the administrative boundary is there, then it should clip the selected area according to administrative boundary. In GIS software, it is possible to extract the region of interest (ROI). This ROI consist two types of features the first one is polygon feature and second one is line feature. The polygon feature represents the Jalandhar City boundary, from this City Boundary was extracted. The line feature represents the Transport Network of Jalandhar City. By using the Jalandhar City boundary, the road line feature were clipped and saved with a different name, so it shows only the Road Network which comes within the Jalandhar City boundary as shown in Flow chart no. 1. Methodology of Network Analysis. In figure 2, it basically shows the geospatial location of Schools in Jalandhar city with the help of point location and in figure 3, it mainly shows the location of Hospitals in Jalandhar and in figure 4, it mainly shows the locations of Fire stations in Jalandhar. These geospatial locations of the different three types of 
service area are procured with the help of Google maps for the research purpose only and with the help of their analyses on GIS software it basically shows the importance of network analysis technology of GIS in Jalandhar City. Which have advantage in daily life for Police department and for public also.

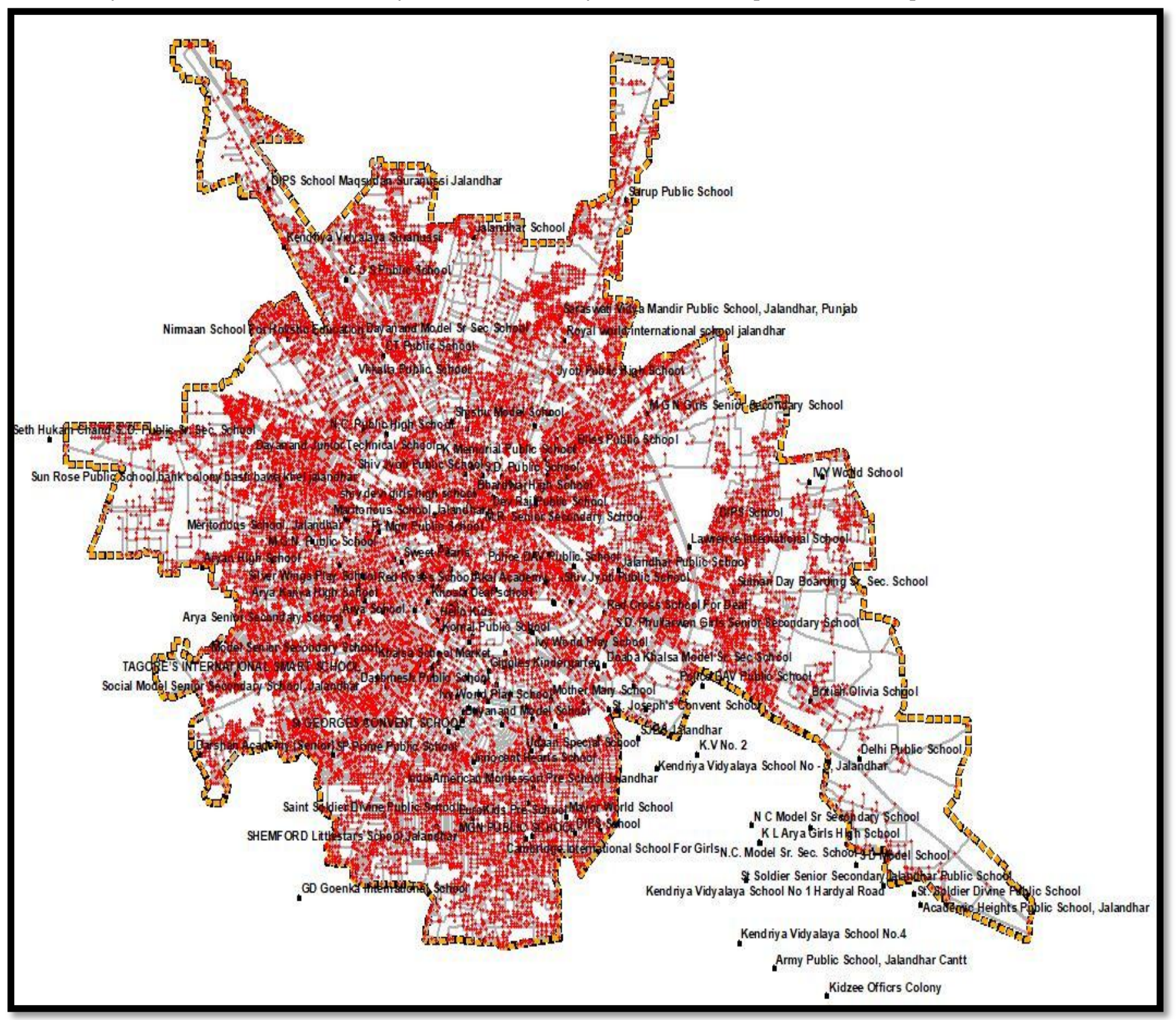

Figure 2: School/Education Institute Data of Jalandhar City on GIS Map 
International Journal of Research in Advent Technology, Vol.7, No.6, June 2019 E-ISSN: 2321-9637

Available online at www.ijrat.org

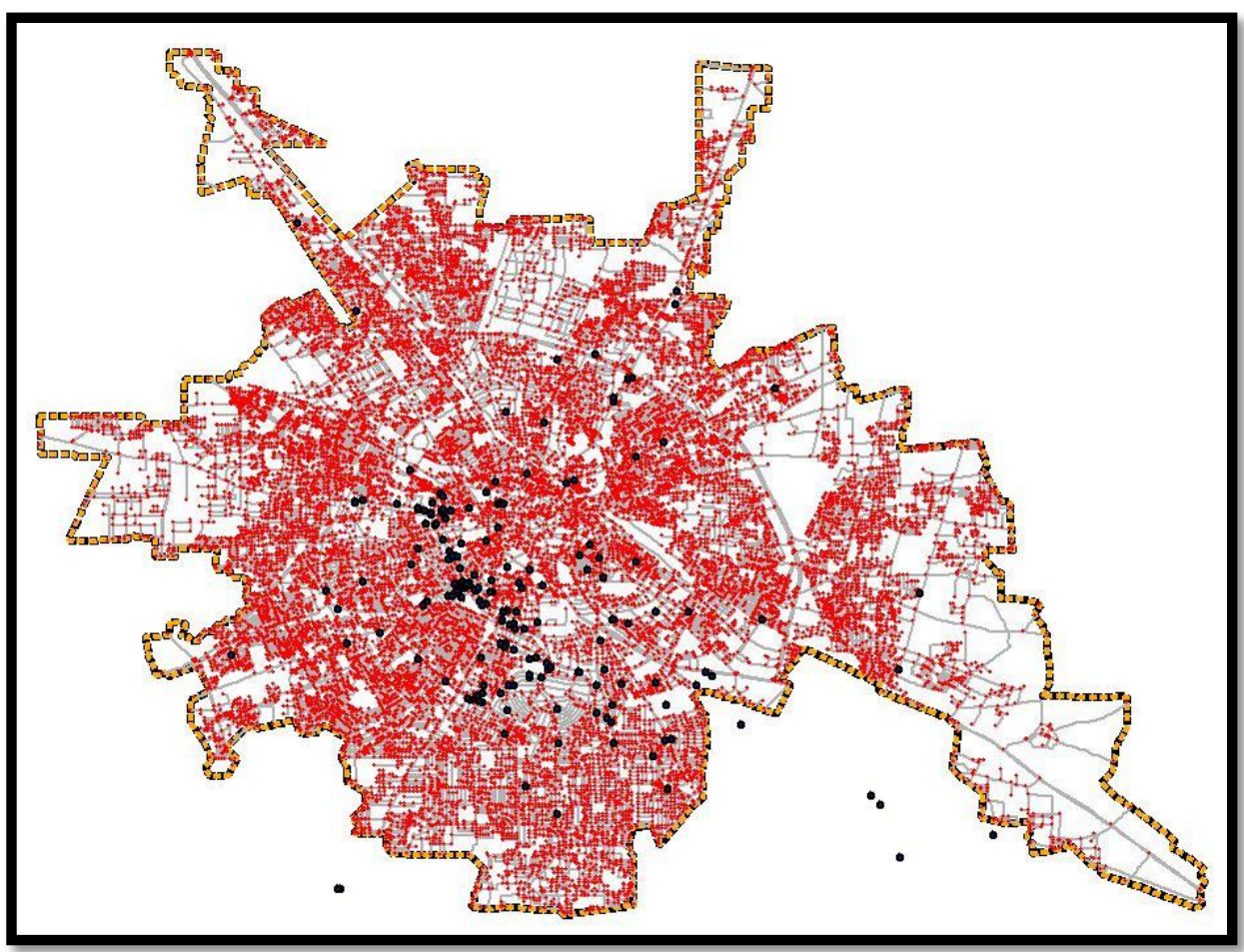

Figure 3: Hospitals Data of Jalandhar City on GIS Map

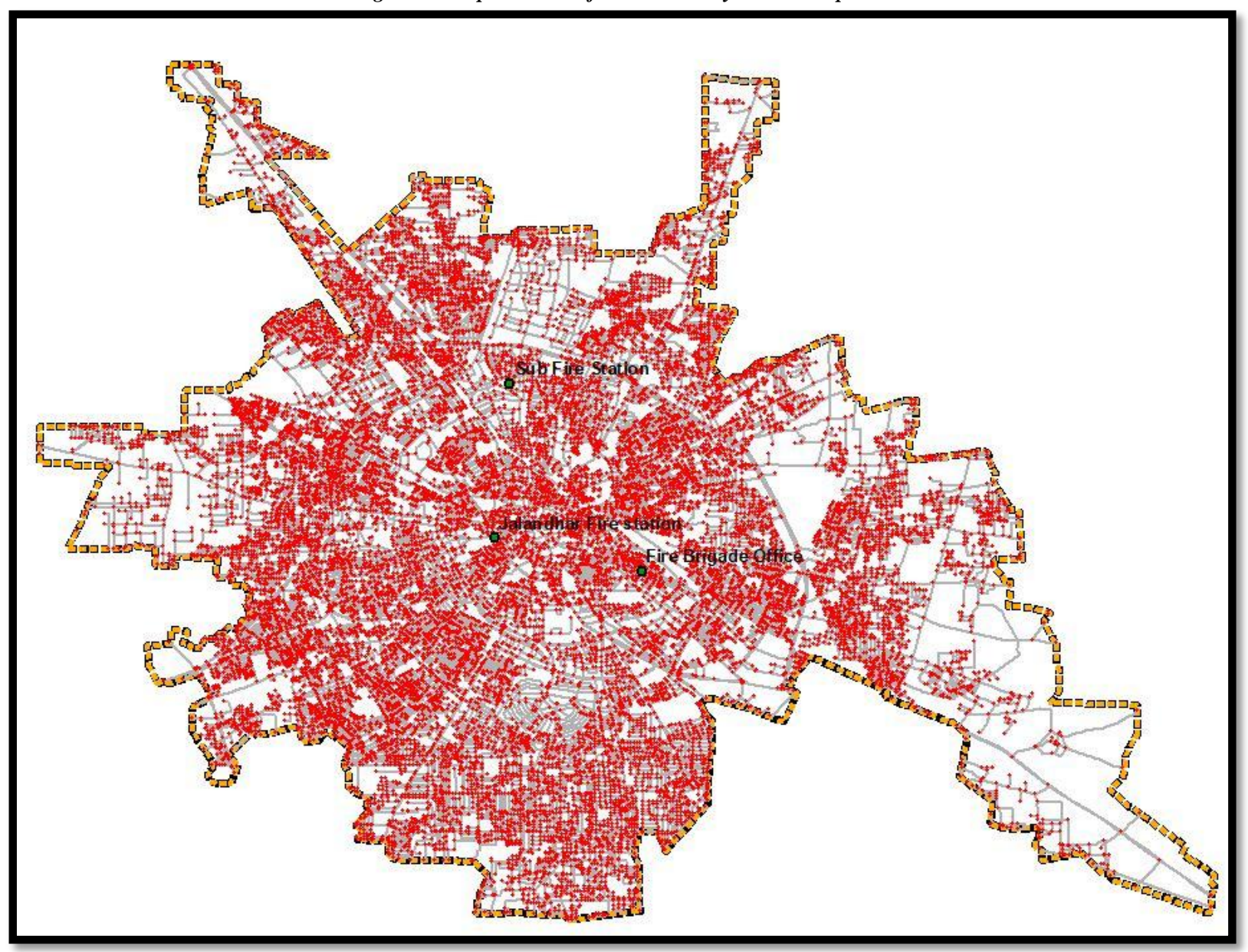

Figure 4: Fire Station Data of Jalandhar City on GIS Map. 
International Journal of Research in Advent Technology, Vol.7, No.6, June 2019

$$
\text { E-ISSN: 2321-9637 }
$$

Available online at www.ijrat.org

\section{B. Dataset in Geodatabase:}

The dataset network was created in a Geodatabase that supports different corner, turn and intersection sources. Adding the different attributes in the attribute table of the shape files with different services names as for Schools, Hospitals and Fire Stations etc. as example shown in figure 5.

\begin{tabular}{|c|c|c|c|c|c|c|c|}
\hline & ObjectID & Shape & Name & SourcelD & SourceOID & PosAlong & SideOfEdge \\
\hline$p$ & 1 & Point & Apeejay School Jalandhar (Mahavir Marg) & Road & 117 & 0.710436 & Left Side \\
\hline & 2 & Point & Academic Heights Public School, Jalandhar & Road & 922 & 0.824565 & Left Side \\
\hline & 3 & Point & Army Public School, Jalandhar Cantt & Road & 935 & 1 & Right Side \\
\hline & 4 & Point & Eklavya School Jalandhar & Road & 1504 & 0.18578 & Left Side \\
\hline & 5 & Point & Delhi Public School & Road & 59 & 0.147044 & Left Side \\
\hline & 6 & Point & Apeejay School Jalandhar (Tanda Road) & Road & 90 & 0.536636 & Left Side \\
\hline & 7 & Point & BSF Senior Secondary School & Road & 924 & 0.543279 & Right Side \\
\hline & 8 & Point & Swami Sant Dass Public School & Road & 1901 & 0.31475 & Right Side \\
\hline & 9 & Point & M.G.N. Public School & Road & 8836 & 0.761856 & Left Side \\
\hline & 10 & Point & CT Public School & Road & 2483 & 0.996531 & Right Side \\
\hline & 11 & Point & Police DAV Public School & Road & 5100 & 0.149082 & Right Side \\
\hline & 12 & Point & IVY World School & Road & 6159 & 0.482247 & Right Side \\
\hline & 13 & Point & Police DAV Public School & Road & 3450 & 0 & Left Side \\
\hline & 14 & Point & Mayor World School & Road & 668 & 0.634812 & Right Side \\
\hline & 15 & Point & Lawrence International School & Road & 3355 & 0.900725 & Left Side \\
\hline & 16 & Point & British Olivia School & Road & 10983 & 0.424474 & Left Side \\
\hline & 17 & Point & Cambridge International School & Road & 343 & 0.646151 & Left Side \\
\hline & 18 & Point & Innocent Hearts School & Road & 632 & 0.679093 & Right Side \\
\hline & 19 & Point & Dayanand Model School & Road & 276 & 0.660598 & Right Side \\
\hline & 20 & Point & DIPS School Maqsudan Suranussi Jalandhar & Road & 3007 & 0.308495 & Right Side \\
\hline & 21 & Point & DIPS School & Road & 803 & 0.62858 & Left Side \\
\hline & 22 & Point & C J S Public School & Road & 3031 & 0.220907 & Left Side \\
\hline & 23 & Point & GD Goenka International School & Road & 4837 & 0 & Right Side \\
\hline & 24 & Point & Jalandhar Public School & Road & 922 & 1 & Left Side \\
\hline & 25 & Point & Shiv Jyoti Public School & Road & 2249 & 0 & Left Side \\
\hline & 26 & Point & Cambridge International School For Girls & Road & 449 & 0.066368 & Right Side \\
\hline & 27 & Point & Sanskriti KMV School & Road & 5342 & 0.119412 & Left Side \\
\hline & 28 & Point & St. Joseph's Convent School & Road & 41 & 0.368166 & Left Side \\
\hline & 29 & Point & Delhi Public School & Road & 9382 & 0.291118 & Right Side \\
\hline & 30 & Point & St. Soldier Divine Public School & Road & 2161 & 0.547844 & Left Side \\
\hline & 31 & Point & S D Model School & Road & 11064 & 0.198731 & Right Side \\
\hline & 32 & Point & Social Model Senior Secondary School, Jalandhar & Road & 4744 & 0.410763 & Left Side \\
\hline & 33 & Point & Little Blossoms School & Road & 498 & 0.650683 & Right Side \\
\hline & 34 & Point & Guru Amar Dass Public School & Road & 276 & 0.287386 & Right Side \\
\hline & 35 & Point & Apeejay Rhythms Model Town & Road & 293 & 0.37158 & Left Side \\
\hline & 36 & Point & Lala Jagat Narain D.A.V. Model School & Road & 7875 & 0.36768 & Right Side \\
\hline & 37 & Point & Nirmaan School For Holistic Education & Road & 2815 & 0.434505 & Right Side \\
\hline & 38 & Point & Jalandhar Public School & Road & 3536 & 0.559767 & Left Side \\
\hline & 39 & Point & Jalandhar Public School & Road & 171 & 0.02917 & Right Side \\
\hline & 40 & Point & Darshan Academy (Junior) & Road & 1758 & 0.900662 & Right Side \\
\hline & 41 & Point & Arya Kanya High School & Road & 1771 & 1 & Right Side \\
\hline & 42 & Point & Apeejay School Jalandhar (Rama-Mandi) & Road & 2633 & 0.896978 & Left Side \\
\hline & 43 & Point & St Joseph'S Convent Junior School & Road & 76 & 0.964099 & Left Side \\
\hline
\end{tabular}

Figure 5. Adding the School Attributes in the Attribute table

Connectivity for the network dataset was developed using the GIS Connectivity model in conjunction with the elevation field model and for each source of edge and junction, the connectivity policy was determined. Special situations, such as bridges, were also discussed. During network evaluation, the impedances used and their values were determined from the network sources [18].

\section{Creating the Network Dataset}

The next step is a Road Generalization and Network dataset as shown in figure 6. These geometric operations are involved selection, merge, symbolization, elimination etc. The Road Network data having a category Road Type, like 'National Highway', 'State Highway', 'District Road' , 'Major City Roads' and 'sub Roads'. By using this classification the selection process was performed. So only those roads are there which is 'National Highway', 'State Highway', 'District Road' and 'Major City Roads', it means the 'Sub Roads' and those roads are having null value are removed. This process is nothing but Elimination processes all the function classes that were involved in a network as sources were put in one feature dataset. Fields representing network impedance values such as range, travel time, etc. and other network attributes such as one-way, z-elevation, etc $[17,18]$. 


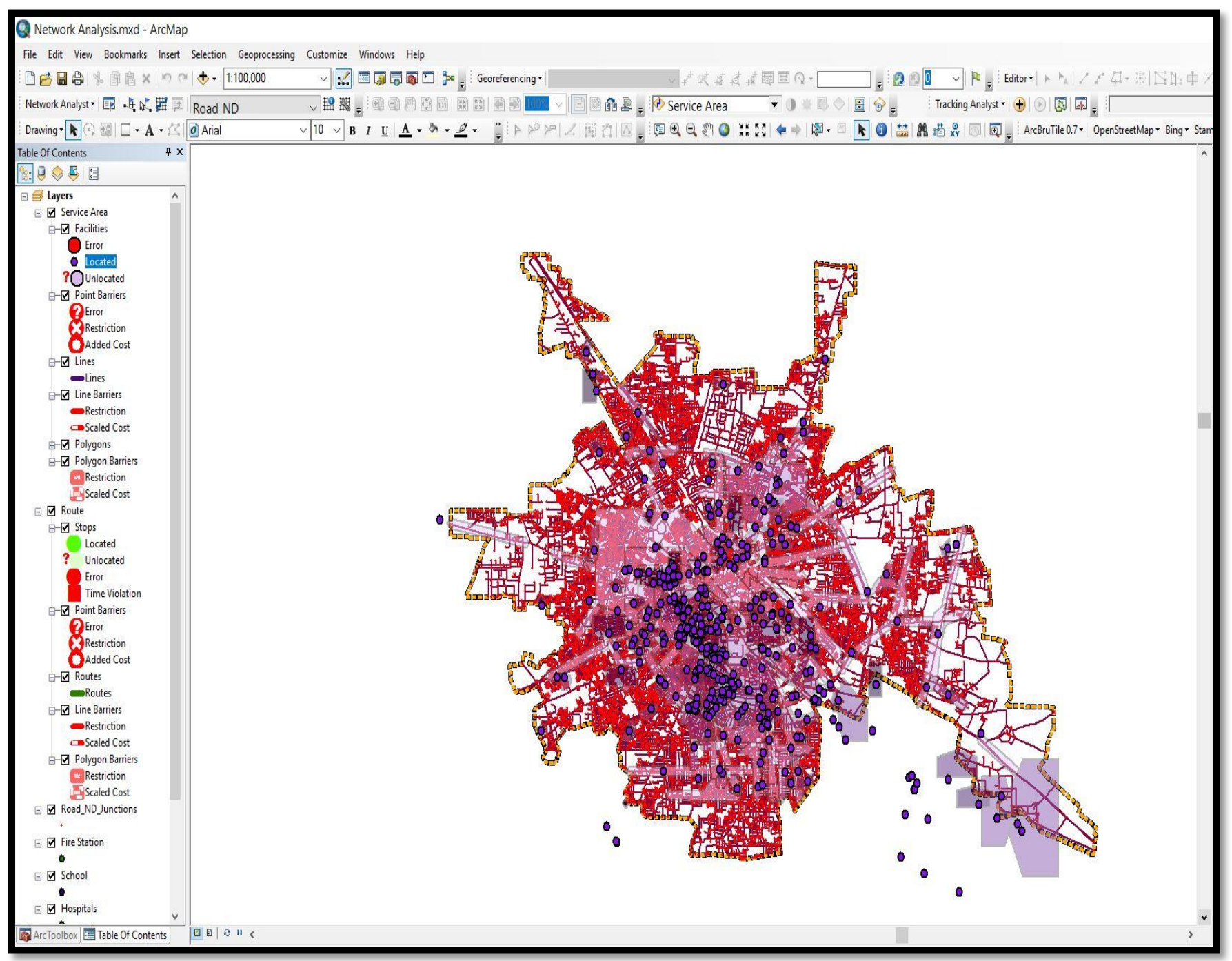

Figure 6. Network dataset

The network was developed using the new Network Dataset wizard by naming the network dataset, identifying network sources, establishing connectivity, identifying elevation information, specifying turn sources, defining characteristics (such as expenses, descriptors, limitations, and hierarchy). It was created after creating a network dataset. Building is a method of establishing network components, establishing connectivity, and assigning values to the characteristics identified. Finally, from the context menu in the Catalog in the GIS Software, fresh turn function class was developed in the Geodatabase [17,18].

\section{USEFUL FOR POLICE DEPARTMENT (TO DifFERENTIATE THE SHORTEST PATH \& BEST ROUTE)}

It is very useful for the daily services providing by the police department to the public at different locations. For this it is urgent for the police department to differentiate the shortest path \& Best route and choose the one path as according to the situation ahead. It has developed after a network dataset has been developed. Building is a technique of setting up network parts, creating connectivity, and assigning values to recognized features. Finally, in the Geodatabase, new turn feature class was created from the context menu in the catalogue. As an example, either the path with the least length (shortest route) will be chosen to navigate from one place to another, or the route with the least duration of travel (best route) will be chosen based on the impedance variable you choose to fix (From Ramamandi, Jalandhar to Patel Chownk Jalandhar). In this assessment, the length of the highway was selected as the impedance factor, the starting time of the journey to 5:00 PM, which is the traffic on the highway network in the Jalandhar City. 


\begin{tabular}{|c|c|c|c|c|}
\hline \multicolumn{5}{|c|}{$\begin{array}{c}\text { Table no. 1: Time taken \& distance covered by a } \\
\text { vehicle in the same network at same time (5 P.M) } \\
\text { in different days of a week. }\end{array}$} \\
\hline \multirow[t]{2}{*}{ Day } & \multicolumn{2}{|c|}{ Shortage Route } & \multicolumn{2}{|c|}{ Best Route } \\
\hline & $\begin{array}{l}\text { Length } \\
\text { (in km) }\end{array}$ & $\begin{array}{l}\text { Time } \\
\text { (in } \\
\text { minute } \\
\text { s) }\end{array}$ & $\begin{array}{l}\text { Len } \\
\text { gth } \\
\text { (in } \\
\text { km) }\end{array}$ & $\begin{array}{l}\text { Time } \\
\text { (in } \\
\text { minute } \\
\text { s) }\end{array}$ \\
\hline Sunday & 9.1 & 47 & 14.5 & 34 \\
\hline Monday & 9.1 & 35 & 14.5 & 25 \\
\hline Tuesday & 9.1 & 33 & 14.5 & 24 \\
\hline Wednesday & 9.1 & 37 & 14.5 & 28 \\
\hline Thursday & 9.1 & 39 & 14.5 & 30 \\
\hline Friday & 9.1 & 35 & 14.5 & 27 \\
\hline Saturday & 9.1 & 45 & 14.5 & 35 \\
\hline
\end{tabular}

Source: Computed Values.

The distance from the shortest path assessment reflects the accumulated lengths of the road sections through which the agents will move. Similarly, the complete route time acquired from the shortest path assessment reflects the accumulated time in minutes for each section of the path over which officials are going to move. It also shows the best path between the two sites. We chose the travel time of the road as the impedance factor in this assessment, and this assessment was conducted simultaneously and as the shortest path assessment over the 7 days of the week. In 7 days from Sunday to Saturday, it has repeated the two analyses for the same two locations and calculated the total distance (in KM) and the average travel time (in minutes) for the two roads obtained. To demonstrate the difference of the best route and shortest route by the values noted down when there is normal traffic on the road network during these time periods. The proportion of supremacy for the highest travel time on the path was calculated using the following formula:

$\mathrm{SP}=\left[\left(\left(\sum_{\mathrm{i}=1}^{9} \mathrm{SRTi} / \mathrm{BRTi}\right)-1\right) / 9\right] * 100 ;$

Such that:

$\mathrm{SP}=$ Superiority Percentage

SRT $=$ Shortest Route Time

BRT $=$ Best Route Time

In emergencies, it is vital to achieve the site of an incident as quickly as possible in order to save people's lives. So, according it is to be noted on the base of this formula of percentage with superiority that the best route is more suitable for being used in emergency situations than the shortest route [17].

\section{RESULTS \& DISCUSSIONS}

\section{A. Finding the Best Route}

The analyst finds the best way or the best path to visit multiple locations from one location to another. The locations were described interactively by placing points on the screen, entering an address, or using points in an existing function class or feature layer. The best route has been determined for the place order as stated by the client. The evaluation may also identify the best sequence to visit the locations. The best route evaluation produces the best route between two places depending on travel time, depending on the traffic circumstances available on the network at a given time of the day. The expansion of the network analyst makes it simple to set the best parameters for rotary evaluation, such as the travel time that will be used as an impedance variable, the travel begin moment that produces distinct outcomes depending on the chosen day profile, Analysis constraints such as highway instructions (unidirectional or bidirectional) and the capacity to disregard invalid network sites that could cause the analysis to fail. We have chosen the start place and the end place after changing the best route analysis settings and then use the best route solver tool to create the best path between the two places.

\section{B. Finding the Closest Facility}

Analysis of the closet equipment discovers the nearest installations that can be reached from an incident place in a particular period based on accessible travel time and traffic information. This helps to understand the nearest equipment from the incident place in emergency cases, In turn, this decreases time, effort, money and saves people's lives [3] as shown in figure 7. The expansion of the network assessment makes it simple to set the analytical parameters for the assessment of the closets, such as the impedance factor in the assessment, the starting time, the time to reach the closets, number of equipment to be found and travel instructions (from equipment to equipment or equipment to incidents). Then, the nearest installations to the place of an incident are to use the network analyst expansion solver [18]. 
International Journal of Research in Advent Technology, Vol.7, No.6, June 2019

E-ISSN: 2321-9637

Available online at www.ijrat.org

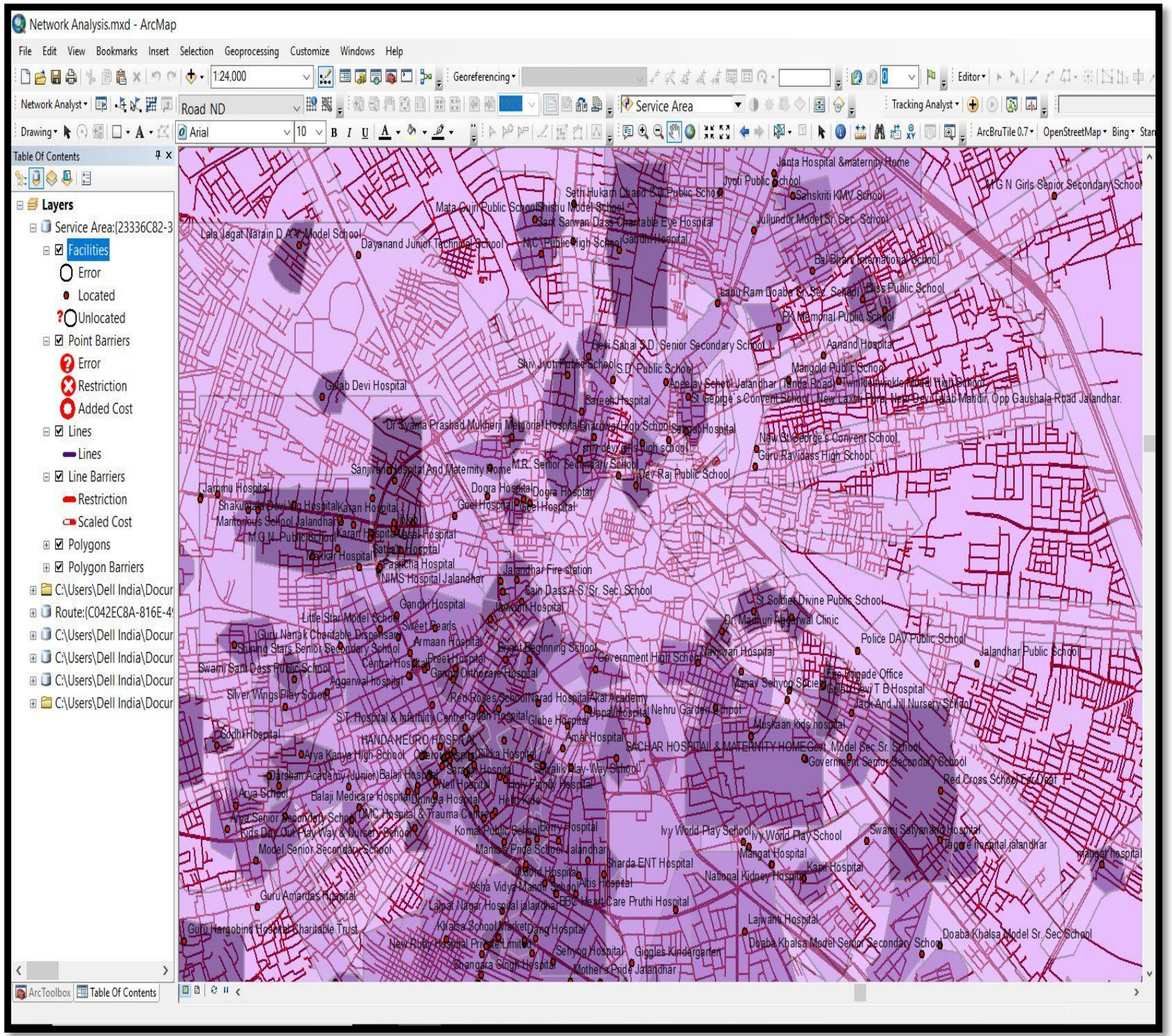

Figure 7: Closest Facility service areas along the specific streets.

\section{Finding Service Areas}

The Analysis will find service regions around any network place. A network service area is a region covering all available roads, i.e. streets within defined impedance. For example, a facility's 10-minute service area includes all the streets that can be reached from that facility within ten minutes. Accessibility relates to the ease of going to a site. Accessibility has been evaluated in terms of travel time in this Analyst. And it can be evaluated on the basis of any other network impedance. Assessing accessibility helps answer some fundamental questions like "How many individuals are within a 10-minute drive from a School or specific clinic?" as shown in figure 8 or "How many residents live within a half-kilometre walk from a City Hospital ?" Also, the examination of accessibility determined how appropriate a site is for a fresh company. It also recognized what is close to a current company to assist you in making other marketing choices [18]. 
International Journal of Research in Advent Technology, Vol.7, No.6, June 2019

E-ISSN: 2321-9637

Available online at www.ijrat.org
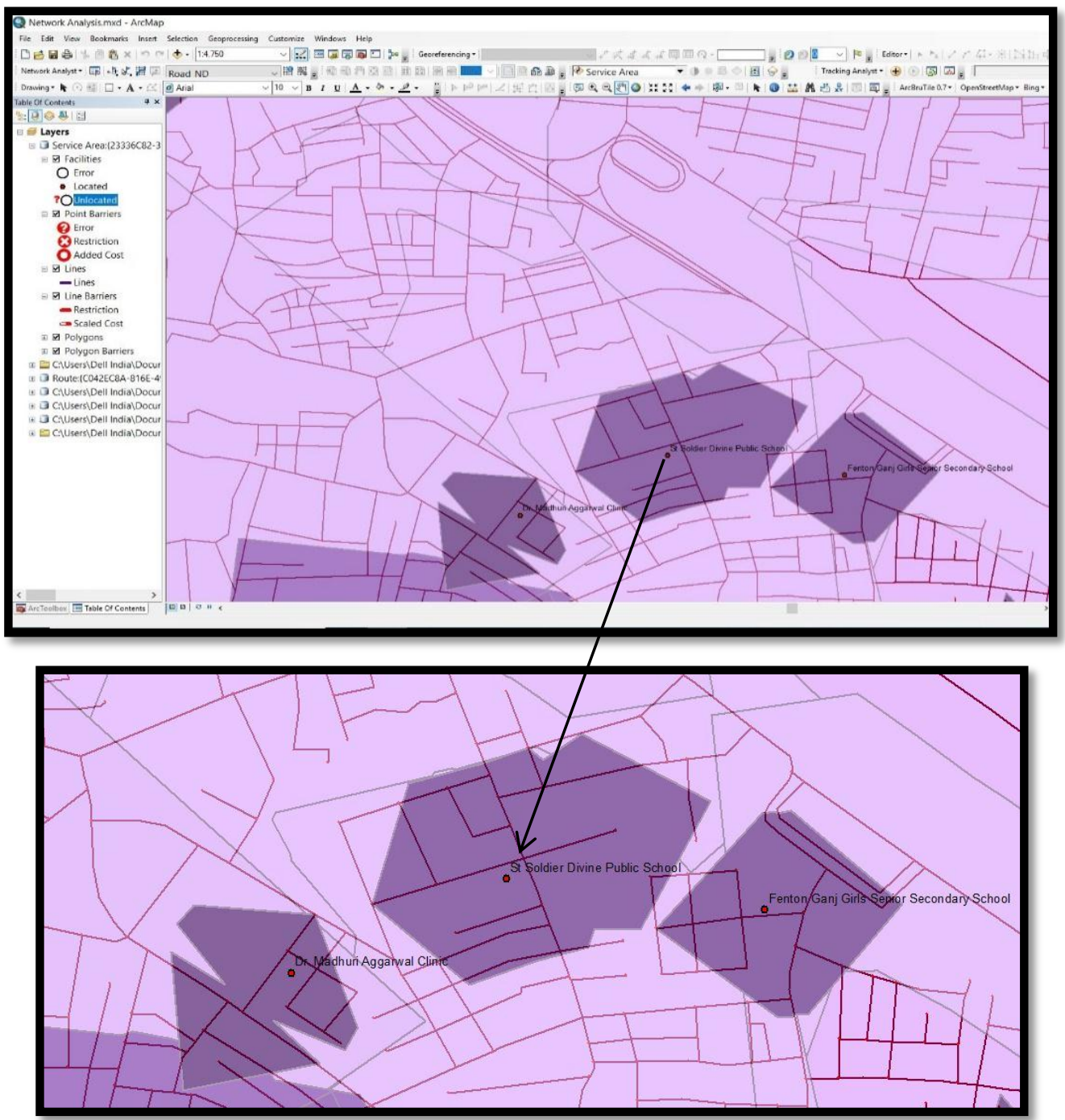

Figure 8: 5 Minutes (Dark in shade) to 10 Minutes (Light in shade) Service areas from the specific Schools and clinics in Jalandhar City.

\section{Evaluating Accessibility}

By a buffer distance around a point, one easy way to assess accessibility.

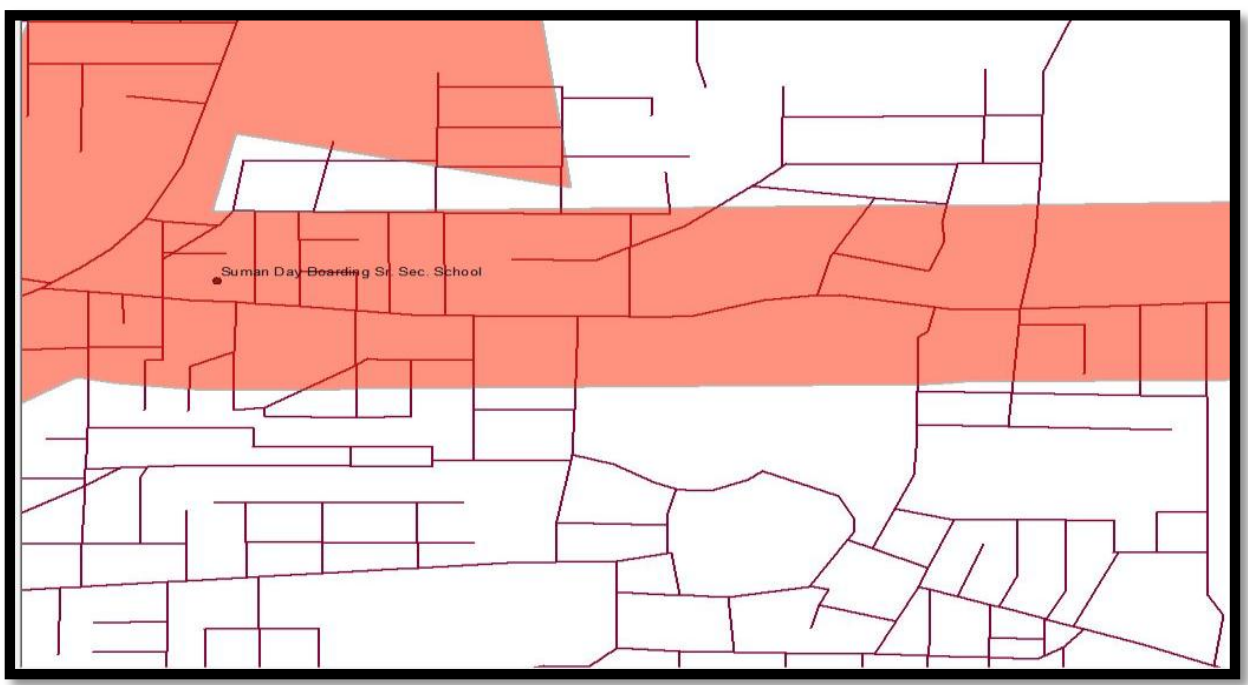

Figure 9: Buffer distance along the School location on the both sides (0.4 KM) from the main road. 
For instance, by using an easy circle, find out how many clients/service areas are within a site's 5-kilometer radius. However, this technique will not represent the real accessibility to the site considering individuals traveling by major road network. An analyst-computed service networks can overcome the limit by finding available roads within five kilometres of a site through the GIS based roads network analysis as show in figure 9. The service networks, for instance, acquire what is next to the available roads [17].

\section{E. Creating an OD Cost Matrix}

The analyst can generate a cost matrix of origin-destination (OD) from various roots to various locations. An OD cost matrix is a table containing the network impedance to each location from each source. It also ranks the locations to which each source links in ascending order based on the minimum impedance of the network needed to travel to each location from that origin.

For each origin-destination pair, the best network route is found and the price is stored in the output line attribute table, which are straight lines. The following graph demonstrates the outcomes of an OD cost matrix assessment designed to determine the cost of reaching the four nearest destinations from each origin. The best community direction is observed for each foundation-destination pair, and the fee is saved inside the characteristic table of the output lines, which are immediately traces. The photo beneath indicates the outcomes of a cost matrix evaluation that was set to locate the fee to reach 11 closest destinations from every origin. The straight lines used symbolize only the different ways, such as by colour, representing the point from which they originate; or by density, representing each path's travel time. Very comparable analyses are performed by the nearest plant and OD cost matrix solvers; however, the primary distinction is in output and computing velocity. The OD cost matrix solver is intended to solve big issues rapidly and therefore does not contain data internally that can be used to produce real route shapes and driving instructions. If driving directions or true route shapes are needed, the nearest facility solver should be used; otherwise the calculation time will be reduced by the OD cost matrix solver [18].

\section{CONCLUSION}

In this article, the GIS-based network evaluation created a set of processes for carrying out an urban area's road traffic network in a GIS setting. The suggested measures include the Selecting and designing the source workspace, identifying the sources and the role they will play in the network, determining characteristics and their values, and analysis. By using GIS software display all the spatial and attribute data about - the road, road type and land use, administrative/ constitutional boundaries etc. It also performs the network analysis on that, so the accuracy of the data will be good and it can be used for further processing. The network analysis is more important because, data can be used in multiple application area like shortest path, tour analysis, etc. After detection of road network with the help of GIS application, still for more accurate network analysis road generalization process should be performed. If there are any errors, it can be removed by applying topological rules. Now the resultant network is perfect for the analysis. The analyses will considerably facilitate decision-making processes by offering helpful data to motorists, other road users, Public/Semi Public Departments, transportation providers, other stakeholders and the people's at large extent. Some of the information that can be obtained from the analyses, among others, are like as the best path (the fastest, shortest, or most picturesque route) to a destination and findings nearest infrastructure (such as a bus stop, police station, shopping Malls, hospitals, etc. $[17,18]$.

\section{REFERENCES}

[1] O. Ameyan, "Environmental and energy issue in urban transport system development," presented at the FUMTA Seminar on Urban Transport Policy for Punjab, Federal Urban Mass Transit Agency, Jalandhar City, Punjab, 16 June, 1996.

[2] I. Heywood, C. Sara, and C. Steve, "An Introduction to Geographical Information Systems", 3rd ed., London: Longman, 1999, pp. 19-33.

[3] A. Gubara, A. Amasha, Z. Ahmed and S. El Ghazali, "Decision Support System Network Analysis for Emergency Applications", Informatics and Systems (INFOS), 2014 9th International Conference on, Cairo, 2014, pp. ORDS-40-ORDS- 44.

[4] D. Richardson. Generalization of Road Networks. (November 2011). [Online]. Available:http://www.ccrs.nrcan.gc.ca/ccrs/tekrd /rd/apps/map/current/genrne.html.

[5] B. Ran and D. Boyce, "Modeling Dynamic Transportation Networks", 2nd ed., New York: Springer, 1996, pp. 55-62.

[6] What is GIS. (July 2010). [Online]. Available: http://www.gis.co m/w hatisgis/

[7] D. W. Rhind, D. J. Maginie and Good Child M. F. "Geographical information systems," Applications, vol. 2, London: Longman, pp. 289-350, 1989.

[8] J. Burrough and B. Claramunt, "A structural approach to model generalization of an urban street network," in Proc. Fifth Annual Conference on Geographical Information Science, Mallorca, Spain, 25-27 April 2002.

[9] N. M. Waters, "Geographical Information Systems", 2nd ed., John U.S.A.: Wiley and Sons Inc., 1998, pp. 42-50.

[10] An illustrated dictionary of geographic information systems. (October 2010). [Online]

[11] AGI GIS Dictionary. (July 2010). [Online]. Available: http://www.geo.ed.ac.uk /agidict / welcom.html

[12] W. B. Hofmann, H. Lichtendgger, and J. Collins. GPS Theory and Practice, New York: Springer, 1993, pp. 21-63.

[13] Eric K. Forkuo and Jonathan A. Quaye-Ballard, "GIS Based Fire Emergency Response System", International Journal of Remote Sensing and GIS, Vol.2, No.1, January 2013, pp. 32-40.

[14] SuneetNaithani, Abhishek Choudhry, Sandeep Chauhan, "Decision Support System for Emergency Response", European Scientific Journal, vol.2, No.3, NOV-DEC, 2013, pp. 680-687.

[15] Dechuan Kong, Yunjuan Liang, Xiaoqin Ma, Lijun Zhang, "Improvement and Realization of Dijkstra Algorithm in GIS of Depot", IEEE, 2011.

[16] Seema Rani (2014), "Monitoring Land Use/Land Cover Response to Urban Growth of the city of Jalandhar using Remote Sensing Data", International Journal of Advanced Research (ISSN 2320-5407), Volume 2, Issue 6, pp-1122-1129.

[17] Sayed Ahmed, Romani Farid Ibrahim, Hesham A. Hefny (2017), "GIS-Based Network Analysis for the Roads Network of the Greater Cairo Area", Proceedings of the International Conference on Applied Research in Computer Science and Engineering ICAR'17, Lebanon, 22-06-2017, published at http://ceur-ws.org.

[18]. Sama'ila Saleh (June,2013), “Geographical Information System (GIS) as a Tool for Urban Traffic Network Analysis (A Case Study of Federal Capital City, Abuja", Vol, 1, No. 1, Journal of Traffic and Logistics Engineering. 
International Journal of Research in Advent Technology, Vol.7, No.6, June 2019

E-ISSN: 2321-9637

Available online at www.ijrat.org

\section{AUTHORS PROFILE}

Harcharan Singh: M.Tech in Urban Planning from GRD School of Planning, Amritsar. M.Sc in Remote Sensing \& GIS from KU, Nainital. Associate Member of ITPI.

Sachin Suryawanshi: M.Sc in Geo informatics from

Pune University and M.A in Geography from Shivaji University, Kolhapur 